\title{
THE USE OF LINE WEBTOON COMIC STRIPS TO UPGRADE STUDENTS' VOCABULARY MASTERY
}

\author{
Luh Putri Maharani \\ English Education, Universitas Negeri Surabaya \\ luh.17020084020@mhs.unesa.ac.id
}

\begin{abstract}
Vocabulary is the key for the learners' language change in learning as a foreign language including English. However, Indonesian students still have problems in vocabulary building, particularly to memorize meaning of new words. This fact implies that they need effective ways to learn vocabulary. It would be more beneficial to use an effective vocabulary teaching technique to help the students in upgrading their vocabulary mastery. The use of relevant media in teaching vocabulary will also boost student's motivation. The aim of this study was to reveal how Line Webtoon comic can be used to teach vocabulary, the student's vocabulary mastery, and the student's responses toward the use of Webtoon comic. The participants in this study were ninth-grade students and their English teacher. This research applied qualitative design. The data was gathered through observation during online learning in Google Classroom, student's task and the interview process. Based on the data, the process of using Line Webtoon for ninth graders was successfully upgraded the students' vocabulary mastery and motivation to read through online comic. It also showed that the students were interested to read because Webtoon consisted of many pictures and they were able to get many new words by using online media.
\end{abstract}

Keywords: vocabulary mastery, media, line webtoon comic strips

\section{Introduction}

Vocabulary has an important role in the EFL classroom, especially in the reading activity Nam (2010). However, eventhough vocabulary is the key for learners' language change, this language component is still being forgotten by some teachers in the classroom. Thornburry (2002) stated that another language components such as grammar, only give a little thing rather than vocabulary since without vocabulary nothing can be delivered. Since vocabulary is not listed as one of the four skills in English, some teachers do not devote enough time to focus in it. It means that vocabulary takes an important role in English. For example, if the students only have a few of vocabularies, they will not be able to deliver their ideas to say, write, and to read in English. It is also difficult to understand the meaning of the words they used or uttered. Vocabulary problem might reduce the students' opportunity to undergo experiences that can develop their ability in using English.

Students with many vocabularies tend to understand materials more easily. Without good vocabulary mastery and strategy, the students get difficulty to catch the meaning. When they do not know how to improve and upgrade their vocabulary, they will have no interest in learning vocabulary. Using beneficial strategy in teaching reading will be more useful to boost the student's interest in the learning process. To maximize the students' interest, teachers must implement innovative teaching and learning methods and increase students' 
desire to learn. The students' enthusiasm in learning can be boosted by using appropriate media in teaching English.

According to Gotsick \& Gotsick (1996), the multimedia and technologies offer the psychologist a variety of opportunities for improving and extending the instructional process. Demonstrations, lab experiments, simulations, electronic term papers, interactive courseware, and many other approaches to teaching become possible. In addition, it is normal to use the appropriate media into the classroom such as visual, audio visual media and many more. This is one of the reasons that teaching with media is very helpful for the students because it is friendly user. Furthermore, the use of media as an effective tool for increasing students' curiosity and encouragement, as well as assisting teachers in effectively delivering materials to them.

A study which was conducted by Khoiriyah (2011) stated that Comic Strips can support the students in improving their vocabulary through visual media (pictures). The story of Comic Strips made the students easily understand about the meaning because comic as a favorite learning media to interest them. One of the features of a comic story is that it creates a fun and relaxed learning environment Superior \& González, n.d (2013). It is colorful with many illustrations, has a simple theme and plot, and also the characters of the story which will attract the students who read it and draw their interest. Comic also tells a story by mentioning the characters and narrating each part of the story with many pictures and the reader doesn't have to imagine. It is also stated by Rokhayani et al. (2014) that students will be able to deal with formal and informal language with the aid of this comic. To comfort learners' in solving the problems in reading activity and improve their vocabulary mastery, the researcher then choose that it would be easier for them to be assisted in expanding their vocabulary mastery through online media. Line Webtoon Comic Strips as a supporting reading material will give some benefits to the students to upgrade their vocabulary. The students can find some story by using Line Webtoon as an enjoyable medium for teaching reading ability to be quite interesting. Students would be more interested in learning if they use Line Webtoon comic, for example they will get something new, unique in the comic, and feel more enthusiast with the teacher's strategy in introducing and upgrading their vocabularies. Most of the studies also have focused on the beneficial use of technique and media to improve the students' reading comprehension and vocabulary, rather than the disadvantages or challenges for the teachers who apply the media in their teaching learning process. To support these statements, a research conducted by Fauziah (2017) found that by using comic strips are more useful and interesting to be taught for eight graders and it is more attractive because it is easier to use. It is also can be connected with the gadgets and Wi-Fi connections. Through this way, the students will not feel bored anymore.

In light of the background above, the researcher is eager to perform the study on whether Line Webtoon comic strips helped the students to expand their vocabulary mastery during online learning. This learning media could be 
seen as a support to the vocabulary instruction that teachers provide to their students. This study has been designed to answer the following research questions :

How can Line Webtoon comic help students to improve their vocabulary mastery in Junior High School?

What are the students' vocabulary mastery outcome when using Line Webtoon comic?

How are the students' responses toward the use of Line Webtoon comic to upgrade their vocabulary mastery?

\section{Method}

As mentioned previously, the aim of this study were to know the process of using Line Webtoon online comic to upgrade the student's vocabulary mastery, to know the students' result while using Line Webtoon comic in learning vocabulary, and to know the students' responses while using Line Webtoon to upgrade their vocabulary mastery. The researcher wanted to present and describe the use of Line Webtoon, the result of the student's vocabulary task and responses of teacher and students in using this online media in teaching ad learning vocabulary in narrative text. Since it can illustrate the problem and provide detailed in this research, the qualitative design was chosen. The subjects of the study were an English teacher and 32 ninth-grade students from Gresik, East Java. The researcher observed these subjects in order to find out how the teacher used Line Webtoon comic which can help the students to upgrade their vocabulary mastery in learning English. The researcher purposely choosed this level because the first is based on the teacher's recommendation that Line
Webtoon online comic will be very helpful for the students to increase their motivation in reading through picture series and upgrade their vocabularies and this school tried to maximize the online learning through online media besides Google Classroom, Google Meet and Zoom application. Second, according to the Indonesian curriculum, teaching reading and vocabulary narrative text begins in the ninth grade.

The data collected by the researcher in qualitative research was in the form of terms, phrases, and sentences. The results of the students' vocabulary which was presented three times in a month, as well as the results of teacher and students' interview, were used to compile the data for this report. The result of the interview obtained by asking and recording their opinions while using Line Webtoon by Whatsapp Voice Notes.

The instrument which is used in this research is vocabulary task in every meeting which administered in the $9 \mathrm{C}$ students of 10 multiple choice and 10 fill in the blanks. The task is consisted of new unfamiliar words that developed in a sentence from each episode in Line Webtoon Comic such as "We still need to hurdle over one more step to friendshiphood. The word friendship means...". The researcher also used online questionnaire which is delivered in Google formulir to answer the third research questions toward the use of Line Webtoon in online class which consists of 10 short questions to know the students' perception in learning vocabulary. The researcher also used the interview guidelines in order to make some questions as a preparation before interviewing the participants consisted of 8 questions for the teacher 
and 8 for the students. The aim was to investigate the teacher's obstacle towards the use of Line Webtoon application and the students' responses towards the use of this online media. Thus, when the interview is conducted, the researcher can ask the respondents smoothly by looking at the guidelines. For the first research question, the researcher did online observation through Google Classroom and joined into Whatsapp Group to get detail information about the teacher's instruction while delivering material in Google Classroom and online task for the students by taking notes about the teacher's strategy while using Line Webtoon Comic in teaching vocabulary.

This study used three steps as organized by Ary et al., (2010) which were familiarizing and organizing, coding and reducing, interpreting and representing. In the coding and reducing, the researcher assigned some codes to the data result that have been organized based on the date and month during Online Observation through Google Classroom in order to make it organized and safed in some folders included the documentation of online learning such as student's photos while reading Line Webtoon comic at home.

For the second research question, the researcher organized the data about the student's online vocabulary task result from the first meeting until the end of the online research by creating some tables. There was not confusion found while organizing the data. In line with the third research question about the student's responses while using Webtoon comic, the researcher transcribed the data from the interview without modifying the sentences or phrases as the part of familiarizing and organizing process. After that, the researcher organized the result of interview by transcribing from Whatsapp voice notes recordings in written and finally save the data with its original file name such as the interview videos, interview recordings. The researcher also reduced the inappropriated information and will minimize the unimportant data then interpreted the data from the interview results by explaining the teacher and students' real answers from both the questionnaire and interview phase. Finally, the researcher presented the data in the form of sentences, by adding some tables and pictures during online observation as supporting data to explain the teacher's obstacle and the student's feelings towards the use of Line Webtoon application in teaching vocabulary.

\section{Finding and Discussion}

\subsection{Line Webtoon Comic Strips can Help} Students to Improve Vocabulary Mastery

The observation results are presented separately based on the meetings. Three meetings were completed. The teacher gave the students the material and instructed them to read narrative story about "A Budgie's Life" Line Webtoon application from the 1st until 15th episode in the Google Classroom platform. The teacher started to give the first material with clear instruction about comic story from webtoon, did online attendance, then gave the student task in Google Formulir about webtoon vocabularies. The teacher has choosen the title in Line Webtoon because it was related to the narrative text and appropriated to the students' need that 
most of them liked humorous genre so that Line Webtoon could help the students which is provided with various genre of story based on the student's need.

According to Hedge (2013), the teacher should select fascinating texts and a variety of stories for the students to learn. Rozimela (2014) points out that the genre of the story in the comic can increase the student's motivation to read and overcome the difficulties. It was a great strategy for the teacher not to explicitly explain the text, so the teacher used some other vocabularies within the comic to trigger the students and make them to anticipate the flow of the story. As stated by Heinich et al., (2012) that the most common use of media is for supporting the teachers in the classroom to achive the goal of learning. It also supported by Smaldino \& Lowther (2007) that visual media is the most engaging for teaching English because pictures represented and provided details. The teacher instructed the students to access the internet using their smartphone to the Line Webtoon comic so they understood what kind of media they used by downloading the application or accessing on the internet. Teachers believed that by using technology in learning, the students did not feel bored and it can establish good learning atmosphere. After allowing the students to access the media, the teacher asked them to search for the unfamiliar words by practicing the task on Google Formulir, which helped them to improve their vocabulary mastery. At the first meeting, the students seemed difficult to find out the meaning of unfamiliar words from "A Budgie's Life" story, but the teacher let them to find out the meaning by opening their dictionary. They felt confused when reading the story because they found difficulties in understanding vocabulary, finding specific information and understanding the meaning.

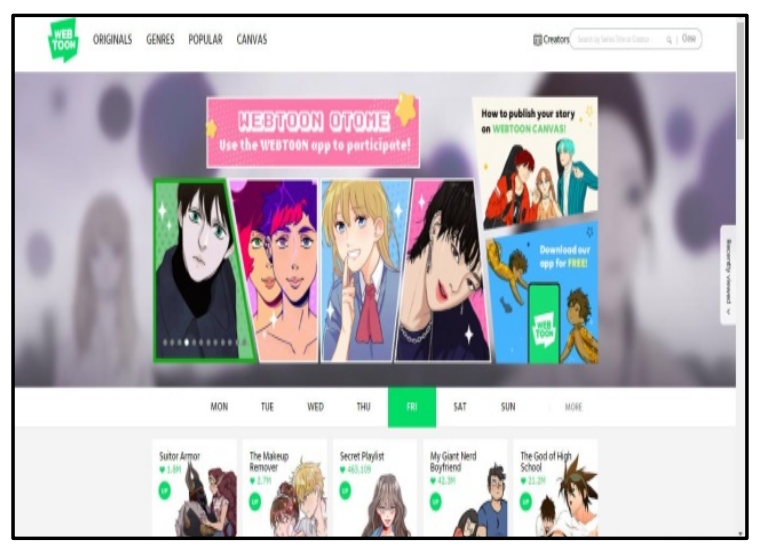

Figure 1. Homepage of Line Webtoon Comic application

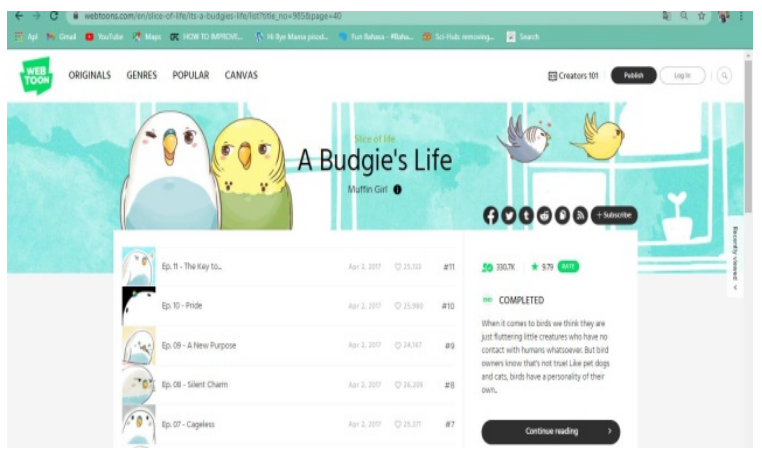

Figure 2. A Budgie's Life Story from Line Webtoon application

The students' comprehension at the second and the third meeting were also getting better after the teacher asked some questions in Whatsapp Group about new vocabularies that they got from 6th10th episode. It can be seen from the online vocabulary task that most of them got the improvements with the highest score 95 (categorized as very good). The students read the story from Webtoon Comic and they did not feel confused. It showed that they could follow the story by filling out the online task in Google Formulir consisted 20 questions. 
Table 1. List of Vocabulary Words in A Budgie's Life Comic Story

\begin{tabular}{|l|l|l|l|l|l|}
\hline Friendship & Random & Stuck & Clipped & Bought & Flight \\
\hline Landed & Companion & Bonding & Ground & Pride & Assumed \\
\hline Petrified & Superhero & Temporary & Tamed & Creatures & Tiniest \\
\hline Pitiful & Revert & Cage & Attach & Unattainable & Envy \\
\hline Abandon & Timid & Lead & Catch & Wings & Ability \\
\hline
\end{tabular}

At the third meeting, the students were required to demonstrate their vocabulary mastery by completing the questions and participating in Whatsapp Group discussion which they were asked to identify new words and construct sentences based on the teacher instruction. There were some unfamiliar words for the students in the story. They already understand with the flow of the story that "A Budgie Life" story explained about pets (birds), the pet owner, short story about the owner's budgies. When it comes to birds, it is easy to believe they are all fluttering little animals that do not interact with humans, but the bird owners know this is not the case. Birds, for example, have personalities of their own much like cats and dogs. The students also found some familiar words such as "Friendship", "Landed", "Cage", "Attach", "Envy" and the others were new for them while reading the story. As stated Stahl (2000) that the students interacts with vocabulary, the text, skills and background knowledge while reading to construct and predict the flow of the story.

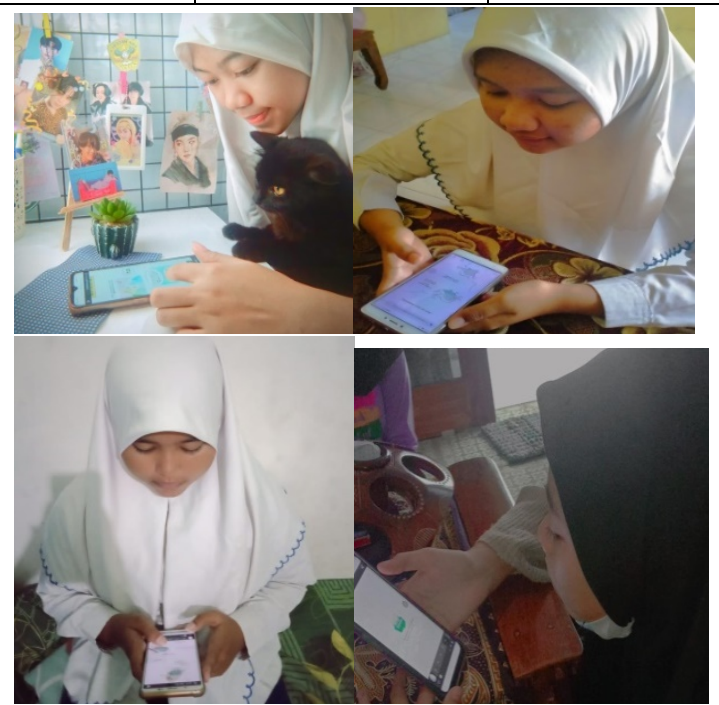

Figure 3. Students read A Budgie's Life story from Line Webtoon

The students have a different perception and imagination about the story, but they finally understood the flow of the story and found some unfamiliar words by translating it into the dictionary so it made them curious and motivated to read the comic. Puspita (2017) points out that it was found using comic strips to develop students' vocabulary and reading comprehension of narrative text was effective. By combining pictures and text, comic was a bridge for the readers which is understandble and educative. When online class started, there were some changes in learning process, but there was no absence. It means that the majority of 
the students actively engaged in online learning.

\subsection{The Students' Vocabulary Mastery after Using Line Webtoon Comic}

The online task provided as indicators of what the students did in those meetings, such as finding new terms, were related to the students' mission, which was completed in three meetings from A Budgie's Life Webtoon story from the 1st until 15th episodes. Here, the students did the online task individually through online Google form to find the meaning of the unfamiliar word from the story. The total questions were 10 multiple choice and 10 fill in the blanks. The students had to complete the online task in about 90 minutes and then apply it in Google Classroom. To read a 25 minutes Webtoon Comic and complete the assignment in 55 minutes. Even though they had to do it online, it was enough for the students to do their best.

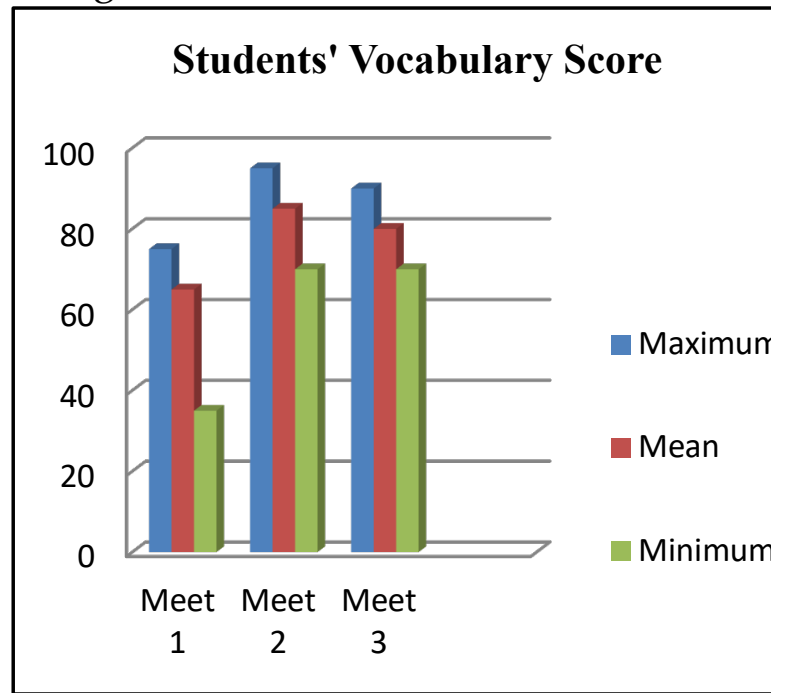

Figure 4. Students' Vocabulary Mastery in 3 Meetings

The chart showed the students found difficulties in understanding new vocabulary at the first meeting. The highest score was 75 (categorized as
Good) and the lowest was 30 (categorized as Poor). They found difficulties to know the meaning of "Companion", "Bonding", "Cage", "Stuck" and "Attach" when they read the first until fifth episode of $\mathrm{A}$ Budgie's Life story. They had to ensure that the word was also suitable with the context from the story. Another difficulty was since it was a little bit difficult if the learners do not know any vocabulary, so they should open dictionary and the meaning in the context. Moreover, some students said that they cannot focus on the new vocabulary, they stated that they more focus on the pictures and there are so many slang words in another episode. Although this media has so many positive sides, it gaves the students bad quality of pictures in the comic if they have a poor signal so they cannot access the comic well. The teacher kept support the students to practice more in getting the new vocabularies and understanding the flow of the story. Sharma \& Unger (2016) stated that the use of smartphone in teaching vocabulary for students also has different sense such as they became enthusiast, interested and also improve their score in online activity. In the second meeting, there were some improvements; the highest score was 95 (categorized as Very Good) and the lowest was 65(categorized as Enough). The teacher kept ask the students to read the next episode, find out and do the online vocabulary task. Mostly they could reach the flow of the story by matching the unfamiliar words with their dictionary. They understood and got new vocabularies such as "Reverted", "Tamed", "Ground", "Bought", "Clipped" and more. They focused the new vocabulary by ensuring the context 
in the story. Hu \& Nation (2000) claimed that students are more likely to comprehend the text if they have a large vocabulary and it is important to ensure that the students can grasp the meaning of the text. According to Ninsuwan (2005), the students difficulty while reading a story occurs in understanding meaning, words and sentences. It also affected to the lack of student's motivation. When the teacher used this media, they also have the newest spirit than before to practice more because they did not feel bored. One of them stated that this Line Webtoon was a perfect combination between web and cartoon story. They learned not only about vocabulary, but also grammar by reading the story slide by slide. There were some words clearly to understand. Thus, it was very helpful for them to improve their understanding the text. This facility make the students feel interested. Most of the students and the teacher agreed that Line Webtoon could sharpening their vocabulary in learning English.

The students assumed that the use of Line Webtoon Comic were pretty to use, fun and interesting and there was a new innovation for the teacher applied it in online learning. It also supported by Khoiriyah (2011) who stated that through visual media or images, comic strips will assist students in developing their vocabulary. Since comics are a favorite learning medium among students, the story of comic strips helped them to understand the passage. Comic also tells a story by mentioning the characters and narrating each part of the story with many pictures and the reader does not have to imagine. It is also stated by Rokhayani et al., (2014) that students will be able to to deal with formal and informal language with the aid of this comic. To comfort learners' to solve the difficulties in reading activity and improve their vocabulary mastery. The students did not have to come to the school, just opened their smartphone from home, online and tap to connect their Webtoon account. They did their best at the third meeting. The previous figure showed the highest score was 85 (categorized as very good) and the lowest was 65(categorized as enough). Line Webtoon already provided a many interesting images that can make them easier memorize new vocabularies quickly. The teacher gave support for them to try their best in exploring new vocabularies inside the story. They already have a better understanding about new unfamiliar words in the table below:

Table 2. Students' Vocabulary Words in the third meeting

\begin{tabular}{|l|l|l|}
\hline Mixing & Satisfy & Squeeze \\
\hline Decided & Territory & Tear \\
\hline Owner & Ignore & Artist \\
\hline Safe & Mention & Aim \\
\hline Dangerous & Poo & Training \\
\hline Worry & Relish & Flew \\
\hline Made & Remind & Transform \\
\hline Worth & Expert & Build \\
\hline
\end{tabular}

\subsection{The Students' Responses towards The Use of Line Webtoon Comic to Upgrade Vocabulary Mastery}

The researcher gave all the students online questionnaire in order to know their opinions and feelings towards the use of Line Webtoon in teaching vocabulary. Besides that, the researcher interviewed the teacher and some of the 
students (4 volunteer participants) contained of 8 questions. In order to obtain more complete and deeper knowledge about the use of line webtoon on the internet, the researcher conducted an interview and followed the interview guideline. The researcher got 4 volunteer students to do the interview. The researcher used Google meet media to interview the EEnglish teacher of $9 \mathrm{C}$ and Whatsapp voice notes for the students. From the interview, the students gave some positive responses such as they like to read Line Webtoon Comic because it was so colorful, has a large number of episodes and picture series, allowing them to quickly understand the story and learn new vocabulary. If the students were having trouble understanding the plot, they could use the picture to guess the text and help them understand. Some students also stated that they mostly like humorous and fantasy genre because they could enjoy learning reading and vocabulary through picture series rather than using the material consisted of full text. They stated that they totally enjoy by using Line Webtoon since the media gave them the story they wanted to read. The students were highly motivated as a result of the interview because a Webtoon Comic is a common comic that can be upgraded and read on their smartphone. To support these statements, a research conduct by Fauziah, (2017) stated that by using comic strips are more useful and interesting to be taught for junior high school students and it is more attractive because it is easier to use. It is also can be connected with the gadgets and Wi-Fi connections. Through this way, the students will not feel bored anymore. The result of the questionnaire and interview will be explained below.

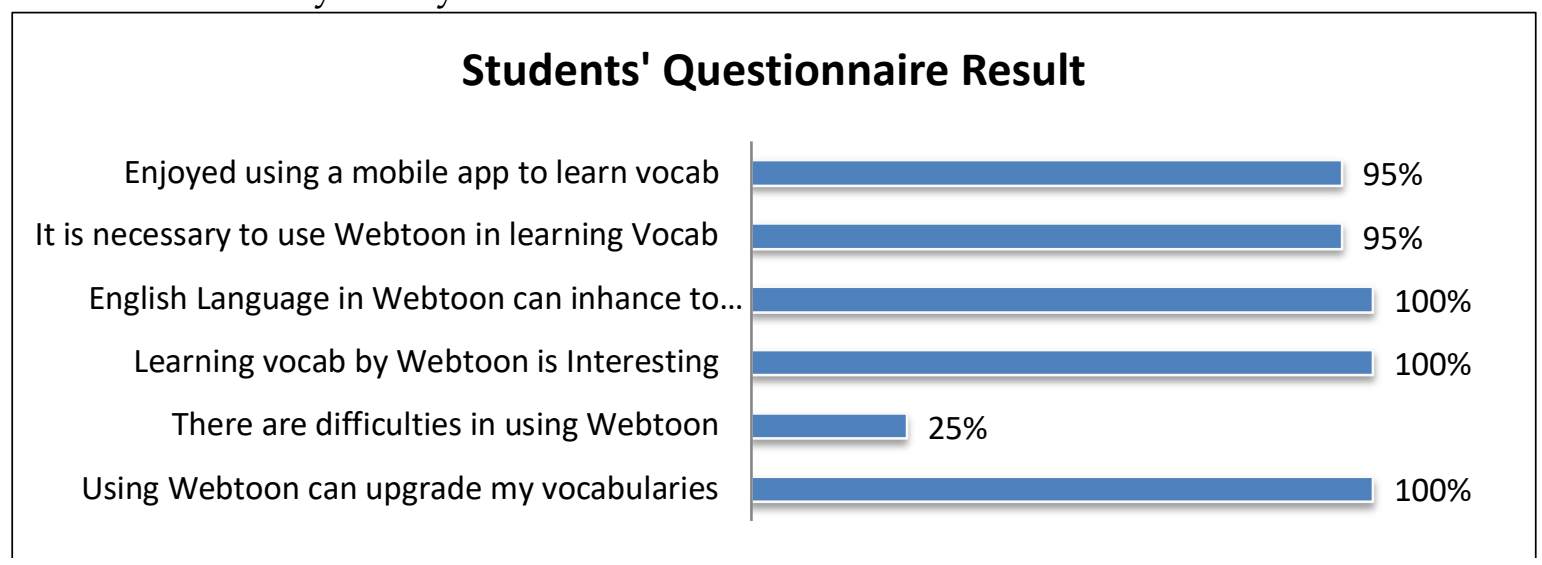

Figure 5. Online Questionnaire Result through Google Formulir

The questionnaire result showed that most of the students totally agree and gave postive responses that they enjoyed using a mobile application to learn vocabulary. Using Line Webtoon comic can upgrade their vocabulary because the application trained them to remember new English words, some of them stated it was a simple and understandable online comic which could boost their motivation to read each episode. Mostly, they did not have any difficulties in operating Line Webtoon because there were some language setting so they can change the language from English to Indonesian. They liked learning vocabulary through this application because it was interesting and attractive which consists of many 
genres (fantasy, comedy, thriller, sci-fi and more). Some of them stated that a good learning process was not only by reading a textbook, but by using this online media which also could help them as a new learning sources in order to train their reading skill. There were also positive vibes and interactions so the students can catch new things while reading this comic. They also agreed that the language use was simple, enhance their motivation to find unfamiliar words so they had better understanding with the meaning. In certain cases, the more vocabulary students know, the more meaning they can communicate as stated by Elfrieda \& Michael (2005). Finally, the ninth grader students were willing to recommend their friends about Line Webtoon online comic as unique, faster, more precise, practical and different vocabulary learning media which could help the teachers in improving their learning strategy in the future. Most of the ninth graders liked to read stories by using Line Webtoon because it can entertain them. The genre of the story was also can stimulated them to get their interest. So the students feel this media was very helpful to know unfamiliar words and understandble although they still have some difficulties to know the flow of the story but they finally overcame and enjoyed the reading.

\section{Conclusion}

It can be concluded that using Line Webtoon Comic Strips in online learning to teach vocabulary for ninth graders helped to improve their vocabulary mastery by finding many unfamiliar word in every episode of "A Budgie's Life" story which also gave positive effect to the students' reading. First, the media was also very easy to use that the students do not need long time to read by using Webtoon. Second, Line Webtoon is an easy media which can make the students comprehend the text because it provided with some languages such as English and Indonesia. Therefore, the teacher's instruction can be understood easily by the students because they already had background knowledge on how to use webtoon comic. Third, it can be seen that using Webtoon Comic to complete the lessons in three meetings was beneficial to the students because they were able gain a deeper understanding of new unfamiliar terms by providing correct answers. Thus, Line Webtoon Comic is proved to have helped them grasp the flow of the story more easily by providing them with some fascinating illustrations. Although there were some difficulties in upgrading vocabularies, they did not affect the student's knowledge. It was proved by the students' score. The result of this study proposes a great recommendation to use webtoon as an online media to explore and upgrade the students' vocabularies.

\section{References:}

Ary, et.al. (2010). Introduction to Research in Education. Eight Edition. Canada: Nelson Education, Ltd.

Elfrieda, H. Hiebert and Michael L. Kamil. (2005). Teaching and Learning Vocabulary: Bringing Research to Practicing London: Lawrence Erlbaum Associates.

Fauziah, N. (2017). the Effectiveness of Using English Comic in Teaching Students, Speaking Ability At Eighth Grade.

Gotsick, J. E., \& Gotsick, P. S. (1996). Multimedia in the classroom. Behavior Research Methods, 
Instruments, and Computers, 28(2), 291-294.

https://doi.org/10.3758/bf03204784

Hedge, T. (2003). Teaching and Learning in the Language Classroom. London: Longman.

Heinich, R., Molenda, M., Russell, J., \& Smaldino, S. (2012). Instructional Media and Technology for Learning. International Journal of Distributed and Parallel Systems, 3, 8.

https://doi.org/10.1016/J.ARABJC.2 011.11 .008

Hu, H.-C., \& Nation, P. (2000). Vocabulary Density and Reading Comprehension. Reading in a Foreign Language, Vol. 13, pp. 403-30.

Khoiriyah, N. (2011). The Use of Comic Stories to Improve Students' Education Faculty.

Nam, J. (2010). Linking Research and Practice: Effective Strategies for Teaching Vocabulary in the ESL Classroom. 28(1), 127-135.

Ninsuwan, P. (2005). The Effectiveness of Teaching English by Using Reading Aloud Techinique towards EFL Beginners. Procedia - Social and Behaviour Sciences, 197(February), 1835-1840.

Puspitasari, Dini (2017). The Use of Webtoon to Improve Students Reading Comprehension. Diakses dari

http://puspitasaridini.wordpress.co $m$

Rokhayani, A., Ririn, A., \& Utari, P. (2014). The Use of Comic Strips as an English Teaching Media. VIII(April), 143-149.

Rozimela, Y. (2014) The Students' Genre Awareness and Comprehension of Different Text Types, International Journal of Asian Social Science, 4(4), 460-469.

Sharma, S. A., \& Unger, S. (2016). Employing web 2.0 technologies to support students' academic vocabulary acquisition. Michigan Reading Journal, 48(3a), 17-29.

Smaldino, S. E., \& Lowther, D. L. (2007). Instructional Technology and Media for Learning. New Jersey: Prentice Hall.

Stahl, S. (2000). National Reading Panel. Great Britain:Pearson Education Limited.

Superior, I., \& González, J. V. (n.d.). The use of comic strips as a means of teaching history in the EFL class: Proposal of activities based on two historical comic strips adhering to the principles of CLIL. 6(2013), 119. https://doi.org/10.5294/laclil.2013.6. 1.1

Thornburry Scott, (2002). How to Teach Vocabulary, Harlow: Pearson Education Limited Longman.

https://www.webtoons.com/en/slice-oflife/its-a-budgies-life/list?title_no $=985$ https://www.webtoons.com/en/comedy/m eow-man/list?title_no $=1677$ 